\title{
The Analysis of Mercury Flow of Fluorescent Lamps in Mainland China
}

\author{
Sha Chen ${ }^{1,}$, Jiaxing Zhang ${ }^{2, b}$ \\ ${ }^{1}$ Key Laboratory of Beijing on Regional Air Pollution Control, Environmental \& Energy Engineering \\ College, Beijing University of Technology, Beijing, China \\ ${ }^{2}$ Institute of Recycling Economy, Beijing University of Technology, Beijing, China \\ aemail: shachen68@163.com, ${ }^{b}$ email: zhangjx29@163.com
}

Keywords: Mercury flow; Fluorescent lamps; Material flow analysis (MFA)

Abstract. Fluorescent lamps are increasingly being used for general lighting due to their higher energy efficiency than incandescent lamps. However, they contain mercury, which is a high toxicity element. China is one of the largest fluorescent lamps consuming and producing country in the world and has been facing a growing concern of mercury pollution. In order to control mercury emissions from fluorescent lamps, mercury flow of fluorescent lamps in China was analyzed using material flow analysis (MFA). As results, it was estimated that the mercury contained in fluorescent lamps of the domestic production, export and import was 29.31, 12.81 and 3.95 tons, respectively. The mercury in the domestic usage was 20.45 tons, of which 3.89 tons to the incineration and 15.54 tons to the landfill at the end-of-life phase, but only 1.02 tons of mercury was recovered. The total amount of mercury emissions to the atmosphere and land was 0.78 and 18.52 tons, respectively.

\section{Introduction}

Mercury is a significant public health and environmental concern because of its toxic, persistent, and bio-accumulative properties [1]. As one of the most toxic elements on the earth, low doses of mercury can exert toxicity on various human organs, including the central nervous system, renal system, reproduction system, immune system, cardiovascular system and motor system [2]. In addition, global warming and climatic changes can accelerate mercury remobilization and bioaccumulation in the environment and ecosystem with increasing risk of human exposure [3]. Therefore, it is increasingly important to reduce the emissions of mercury from human activities. The UNEP (United Nations Environment Program) has determined that mercury compounds are global pollutants and have made efforts to control them. The participants of the Governing Council (GC) 21 in 2001 decided for the first time to push ahead with a GMA (Global Mercury Assessment) and discussed in detail how the global assessment shall proceed. Then the five Global Mercury Partnership Activities were identified at GC 23 (in 2005). At GC 24 (in 2007) delegates from 91 countries and various international organizations formed the first UNEP working group. Participants of GC 25 (in 2009) decided that an Intergovernmental Negotiating Committee (INC) should be organized in 2010 and that the relevant procedures of the Mercury Convention should be concluded by 2013. The first INC meeting was held in Stockholm in June of 2010, and the INC 5, the most recent session, was held in Geneva in January, 2013. Topics at the INC meetings dealt with the current status of mercury emissions and atmospheric releases, methods to reduce emissions and releases, and financial assistance to help countries stay in legal compliance. Governments who participated in INC 5 agreed to the text of a global, legally-binding treaty for the prevention of mercury emissions and release, giving birth to the Minamata Convention on Mercury. The text of the Convention was opened for signatures at the Diplomatic Conference in Japan in October, 2013 [4-7].

Fluorescent lamps (FLs) are increasingly being used for general lighting due to their higher energy efficiency than incandescent lamps. There are several different kinds of fluorescent lamps, including compact fluorescent lamps (CFLs), linear fluorescent lamps (LFLs), and circular fluorescent lamps (CirFLs). However, FLs contain mercury for converting electrical energy to radiant energy in the ultraviolet range and then re-radiating in the visible spectrum [8]. Although the amount of mercury contained in each lamp is relatively small, usually several milligrams, the large market for lighting 
means that significant mercury emissions from FLs can be released into the environment and pose threat to the human being and ecosystems in the end-of-life stage.

Material flow analysis (MFA) method is a tool to analyze the metabolism of social materials and aims to analyze material flows and stocks within a given system, to evaluate the importance and relevance of these flows and stocks, and to control material flows and stocks in view of certain goals [9]. MFA method has been already widely used to understand and analyze the mercury flow. Christensen et al. [10] analyzed the consumption and the disposal of mercury and its release to the environment in Denmark in 2001. It was estimated that the consumption of mercury was between 2.1 and 5 tons each year. The greatest intentional use of mercury was in the mercury amalgam used in dental fillings, and lesser applications included light sources, batteries and so on. The consumption of light sources was 0.06-0.17tons mercury each year. Mukherjee and Zevenhoven [11] investigated on mercury in fly ash and its releases to the atmosphere and soils cross the Indian. Total mercury into the fly ash was estimated at 41.16 tons in 1997-1998 and the projected mercury in fly ash for 2012 would be double to around 80 tons. Cain, A. et al. [12] used substance flow analysis to develop improved estimates of the environmental releases caused by mercury-containing products. For the FLs of the United States in 2005, the total input of mercury was 7.686 tons, and total releases were 7.177 tons. Chang [13] analyzed the fate and management of high mercury-contained lamps, such as cold cathode fluorescent lamps (CCFLs), ultraviolet lamps (UV lamps), and super high pressure mercury lamps (SHPs), from high technology industries in Taiwan. It was estimated that the total mercury contained in CCFLs, UV lamps, and SHPs produced in Taiwan or imported was 0.886 tons in year 2004. And 0.165 tons mercury was wasted, of which 0.14 tons mercury was treated through the industrial waste treatment process while 0.025 tons mercury did not recover. Asaria et al. [14] studied the Japanese mercury flow of mercury-containing products from manufacture to disposal, including FLs, and discuss the current management of mercury-containing hazardous household waste. The amount of mercury from products was about 10-20 tons annually in Japan, 5 tons of which was from FLs. Most FLs were disposed of as waste, and only 0.6 tons of mercury was recovered annually. Chakraborty et al. [15] quantified major transfer pathways for anthropogenic mercury, its emissions to the environment, and storage in products and anthropogenic sinks in India during 2001-2020, and evaluated the potential influence of some control measures. Total mercury emissions in India were approximately 415 tons in 2001, 310 tons in 2010, and were projected to rise to 540 tons by 2020 .

Above all, mercury flow analyses in some countries or regions have been conducted, but few studies only focus on product level mercury flow, such as FLs. In addition, China is one of the largest FLs consuming and producing country in the world. In 2011, domestic production of CFLs in china accounted for over $80 \%$ of the world's production [16]. And FLs are expected to dominate the lighting market in China over the next several years. At the same time, China lacks of efficient recycling systems and infrastructure (e.g., mercury capture and stabilization system) for the spent FLs. And if we consider the fact that the elemental mercury can be long-living in the atmosphere and transported on intercontinental and hemispheric scales [17], it is increasingly necessary to investigate the mercury flow of FLs in China. Therefore, the purpose of this study is to quantify and figure out the fate and flow of mercury in FLs from their manufacture to their disposal using MFA method. The results could offer the reference for the control, management, and treatment of FLs and provide policy makers with a better understanding for reducing release of mercury from FLs.

\section{Methods}

The MFA method includes four major basic steps, namely goal and system definition, data acquisition and inventory, material balances and modeling, and interpretation [9]. We established the mercury flow of FLs among the production, import, export, and waste management in China. The mercury flow from FLs are generally confined to three stages: production, the use phase and the disposal phase of end-of-life FLs. The basic data is most complemented by literature study. The time margin is year 2011 . The mercury flow of FLs is illustrated in Fig. 1. 


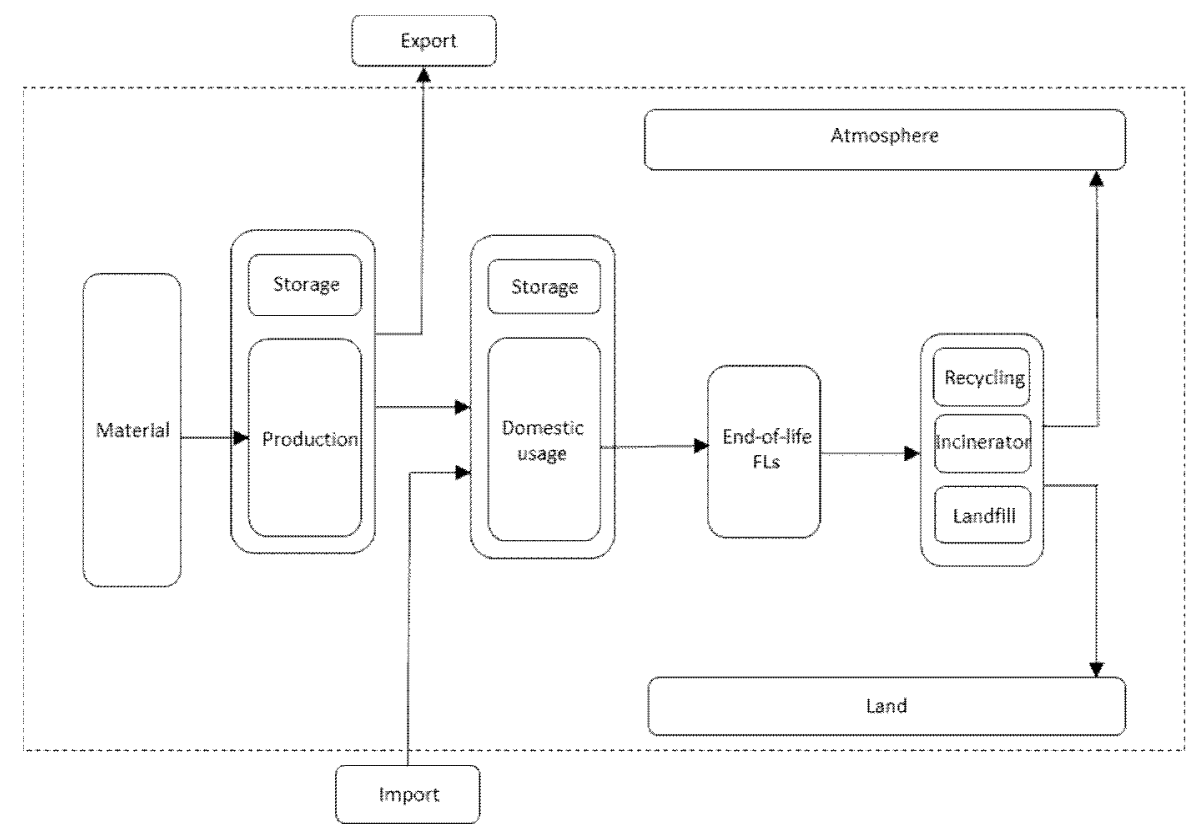

Fig. 1 The model of mercury flow of FLs

\section{Production}

The amount of mercury of FLs in the production, import, export or domestic usage is formulated as the Eq. 1.

$$
\mathrm{E}=\mathrm{Q}_{\mathrm{CFL}} \cdot \mathrm{C}_{\mathrm{CFL}}+\mathrm{Q}_{\mathrm{LFL}} \cdot \mathrm{C}_{\mathrm{LFL}}+\mathrm{Q}_{\mathrm{CirFL}} \cdot \mathrm{C}_{\mathrm{CirFL}}
$$

Where $\mathrm{E}$ is the mercury contained in FLs of the production, import, export or domestic usage. $\mathrm{Q}_{\mathrm{CFL}}$, $\mathrm{Q}_{\mathrm{LFL}}$ and $\mathrm{Q}_{\mathrm{CirFL}}$ are the quantities of CFLs, LFLs or CirFLs, respectively. $\mathrm{C}_{\mathrm{CFL}}, \mathrm{C}_{\mathrm{LFL}}$ and $\mathrm{C}_{\mathrm{CirFL}}$ are the average mercury content per CFL, LFL or CirFL, respectively. According to the industry standard, the mercury content of each CFL should be less than 5mg, and LFL should be less than 10mg [18]. Thus, we consider the average mercury content of each CFL as $2.5 \mathrm{mg}$, and for the LFL and CirFL as 7.5mg, respectively. Amounts of mercury domestic production are obtained from the National Bureau of Statistics [19]. Quantities of FLs in production, import, export and domestic usage in China are obtained from Ref. [20].

\section{The disposal phase of end-of-life FLs}

Waste management of end-of-life FLs has not received sufficient attention in China, and most of spent FLs are discarded as household waste. In the disposal phase of end-of-life FLs, recycling, landfill and incineration as municipal solid waste are taken into account. Obviously, recycling of FLs is more environmentally friendly than the other disposal methods, but it costs more. The proxy data on FLs recycling in China is absence and considering the fact that China is a developing country, so the recycling rate of China was assumed and applied as 5\% [21]. It should be noted that landfill has been the traditional and dominant method of municipal solid waste disposal in China. For the treatment of trash in China, incineration and landfill makes up about $20 \%$ and $80 \%$, respectively. It is assumed that the spent FLs are equal to the quantities of FLs sold in 2011. 


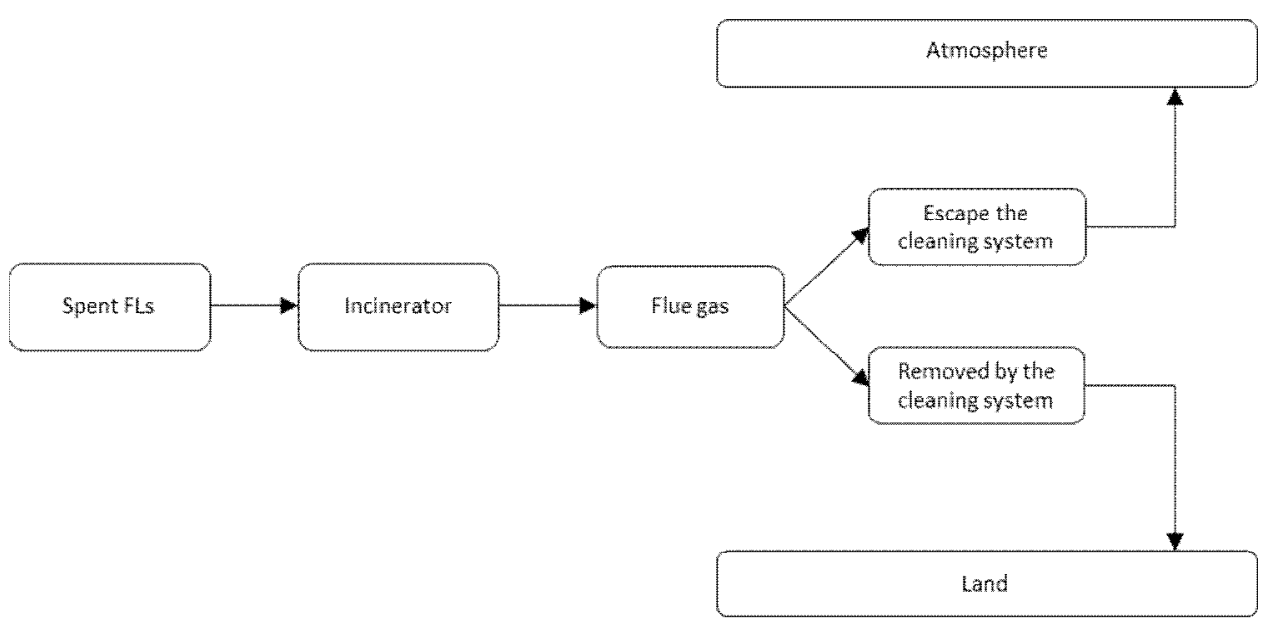

Fig. 2 The scenario for mercury emissions of FLs from incineration

Mercury emissions from the incineration scenario are shown as Fig. 2. Nearly all of the mercury occurring is released to the flue gas upon incineration. Most of the vaporized mercury is removed by the flue gas cleaning system, but a small fraction still escapes from the cleaning system. Flue gas cleaning systems averagely have about $75-82 \%$ mercury removal efficiencies worldwide [22], here we take $80 \%$ as the mercury removal efficiency. For the incineration, except the mercury emitted into the atmosphere, the rest mercury is considered to go to the land.

\section{Results and discussion}

Based on the calculation in part 2, the results of mercury emissions from FLs are illustrated as Fig. 3. Mercury at the raw materials stage of China was around 1492.90 tons in 2011. It was estimated that the mercury contained in the domestic production of FLs was 29.31 tons. The mercury amount in exported and imported FLs was 12.81 and 3.95 tons, respectively. The mercury in the domestic usage of FLs was 20.45 tons, and of which 3.89 tons to the incineration and 15.54 tons to the landfill. It was also investigated that most of spent FLs are disposed as household waste, and only 1.02 tons mercury in FLs was recovered. The total amount of mercury emissions to the atmosphere and land was 0.78 and 18.52 tons, respectively.

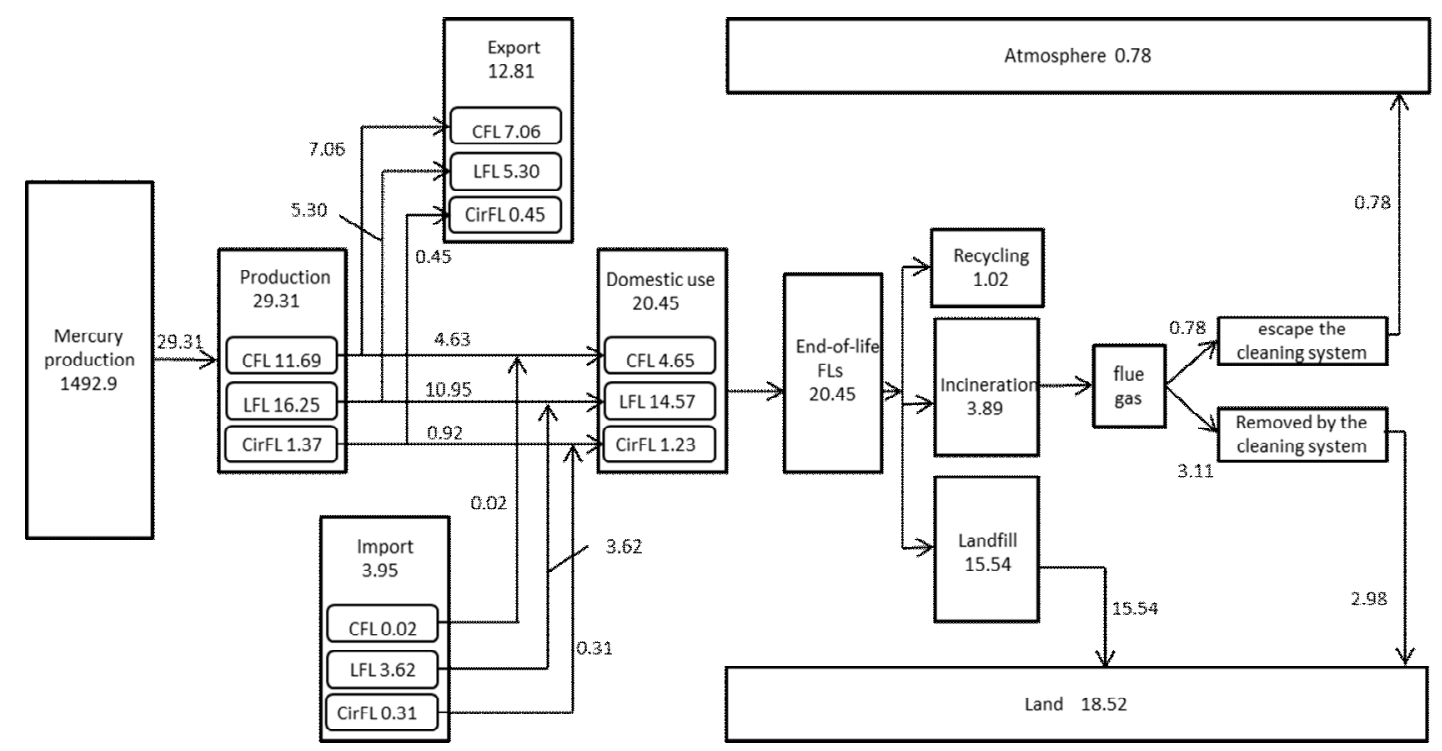

Fig. 3 Mercury flow of fluorescent lamps in China in 2011 


\section{Production}

Currently, mercury has been used in many industries, mainly concentrated in the metallurgical industry, chemical, medical apparatus and instruments, etc. In 2011, the amount of mercury production in China was 1492.90 tons. From the Fig. 4, we can see that the amount of mercury production is increasing rapidly since 2007. The exported mercury was $0.30,0.20$ and 0.03 tons in 2002, 2003, 2004, respectively. From 2004 to now, there is no mercury exported in China. Although the mercury in FLs is only a small part of the total mercury consumption, it is still a serious threat to the environment and human beings considering the high toxicity of mercury.

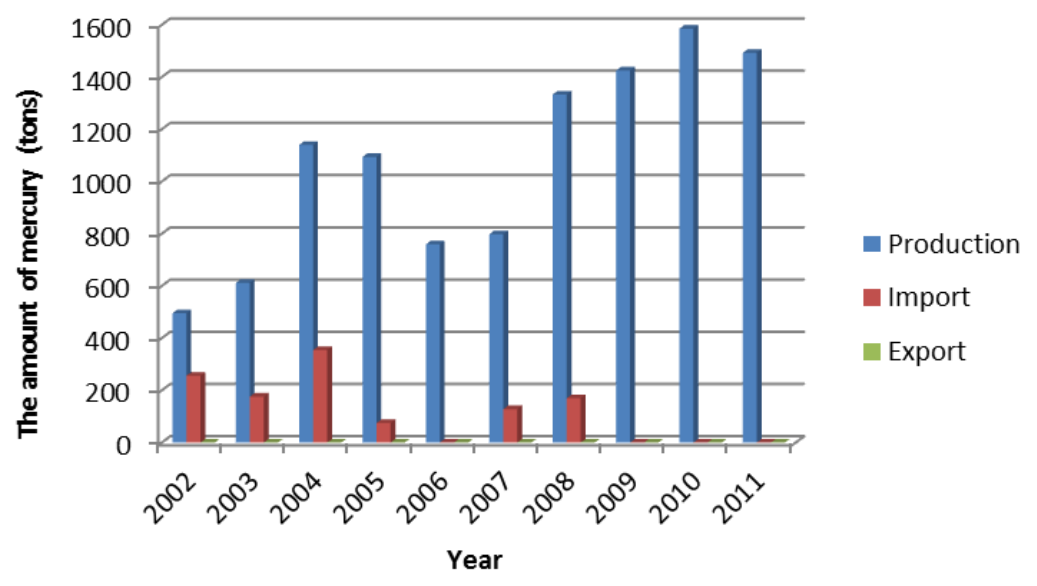

Fig. 4 The mercury amount of domestic production, import and export

In 2011, China produced a total of 7 billion FLs, consuming 29.31 tons of mercury. And 4.4 billion were CFLs, accounting for over $80 \%$ of the world's CFL production [16]. And the number of exported CFLs was 2.8 billion. And the United States was the country that imported largest number of CFLs in 2011. As shown in Fig. 5, the number of domestic FLs production is increasing dramatically from 2002 to 2011, especially for CFLs. This is partly due to the fact that the Chinese government encourages citizens to purchase FLs by subsidy. For the domestic use, CFLs and LFLs account for $46.9 \%$ and $49.0 \%$, respectively. Furthermore, Chinese government officially announced a national roadmap towards phasing out of incandescent lamps on November 1, 2011 [23]. According to the roadmap, the sale and import of incandescent lamps of $100 \mathrm{~W}$ and above, $60 \mathrm{~W}$ and above, and $15 \mathrm{~W}$ and above is going to be banned after October 1 of 2012, 2014, and 2016, respectively [23]. With the upcoming incandescent bulbs phase-out, FLs, particularly CFLs, can dominate the lighting market in China.

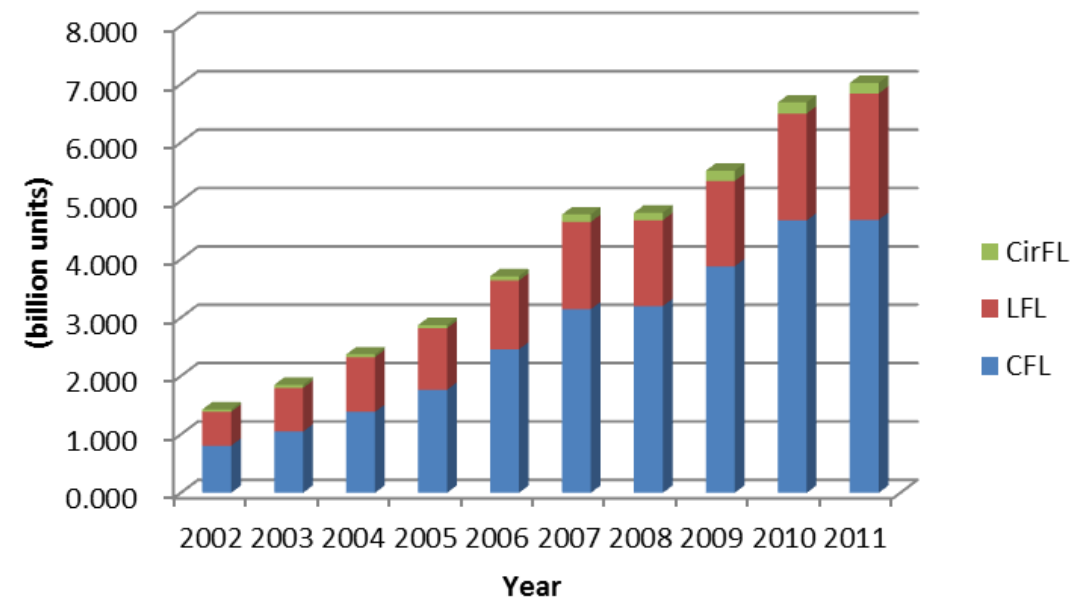

Fig. 5 The domestic production of FLs in China from 2002 to 2011 


\section{The disposal phase of end-of-life FLs}

Waste of spent FLs is one of the fastest-growing waste streams, however, most of spent FLs are discarded as municipal solid waste in China. This is mainly because most areas of China are short of special recycling infrastructure and some citizens' environmental awareness is relatively weak. The amount of mercury disposed by landfill and incineration was 15.54 tons and 3.89 tons, respectively. It should be noted that in the landfill, there is still some elemental mercury in situ, vaporize into the gas phase, or leach out into groundwater [24].

The amount of mercury by recycling was less than 1 ton. Even though the government classifies waste FLs as hazardous waste, so far, China still doesn't have one national regulation on special management for waste FLs, and there are no comprehensive recycling systems for spent FLs. Another reason why FLs cannot be effectively recycled is that some consumers are not well aware of the toxicity of mercury, and some even don't know FLs contain mercury. It was reported that $70 \%$ of the waste FLs was discarded as household waste in Beijing, though about $85 \%$ of citizens were aware of the potential toxicity to the environment and human health of the waste FLs [25]. Obviously, the situations of rural areas are supposed to be worse than Beijing city. It is reported that there are only three companies focusing on recycling lamps in China. And these companies could not get enough quantity of spent lamps to work on, probably because of the high cost of long distance transportation and the lamps breakage during their transportation.

\section{Conclusions}

This study investigated the mercury flow of FLs in China. The major findings are provided as follows:

(1) China has been facing a huge threat of mercury pollution. In 2011, it was estimated that about 7.024 billion were produced domestically, containing total of 29.31 tons mercury. The total amount of mercury emissions to the atmosphere and land was 0.78 and 18.52 tons, respectively.

(2) For the domestic use, the amount of mercury in the LFLs was much larger than that in the CFLs and CirFLs. About half of the mercury amount contained in the domestic production FLs was exported. Compared to export, the mercury in the imported lamps was great less.

(3) It was also showed that most spent FLs were disposed as household waste, and only 1.02 tons mercury was recovered. It is urgent to establish recycling systems to increase recycling rate of spent FLs. To reduce mercury emissions needs the efforts of the policy makers, product manufacturers, and active participation by the general public.

\section{Acknowledgements}

This work was financially supported by the Study of Adapting to The Climate Change on the Energy Sector in Beijing (40005011201504).

\section{References}

[1] Tchounwou, P. B.; Ayensu, W. K.; Ninashvili, N.; Sutton, D. Environ. Toxicol. Vol.18 (2003), p. $149-175$

[2] Zahir F, Rizwi SJ, Haq SK, Khan RH. EnvironToxicol Pharmacol. Vol.20 (2005), p.351-360.

[3] Raposo, C., Roeser, H.M. Waste Manage. Vol.21 (2001), p.661-670

[4] UNEP. Technical Background Report to the Global Atmospheric Mercury Assessment(2005)

[5] UNEP. Chemicals management, including mercury, 25/5, Governing Council of the UNEP(2009)

[6] UNEP. Report of the intergovernmental negotiating committee to prepare a global legally binding instrument on mercury on the work of its fifth session, UNEP (DTIE)/Hg/INC.5/7 (2013) 
[7] UNEP. Global Mercury Assessment 2013, Sources, Emissions, Releases and Environmental Transport (2013)

[8] M. Aucott, M. McLinden, M. Winka. J. Air. Waste Manage. Vol.53 (2003), 143-151.

[9] C. Hendriks, R. Obernosterer. Local Environ. (2005), p.311-328

[10] Christensen CC, Skarup S, Maag J, Jensen SH. Mass flow analyses of mercury 2001. Danish EPA report on Environmental Project:917 (2004)

[11] Mukherjee AB, Zevenhoven R. Sci. Total Environ. Vol.368 (2006), p.384-392

[12] Cain, A.; Disch, S.; Twaroski, C.; Reindl, J.; Case, C. R. J. Ind. Ecol. Vol.11 (2007), p.61-75.

[13] T.C. Chang, S.J. You B.S. Yu, H.W. Kong . Journal of Hazardous Materials. Vol.141 (2007), p.784-792

[14] Asari, M., Fukui, K., Sakai, S.-I. Sci. Total Environ. Vol.393 (2008), p.1-10

[15] Laura Burger Chakraborty, Asif Qureshi, Carl Vadenbo, and Stefanie Hellweg. Environ. Sci. Technol. Vol.47 (2013), p.8105-8113

[16] In Chinese. Ministry of Industry and Information Technology. Roadmap on gradually reducing mercury content of FLs. (2008)

[17] Dastoor, A. P.; Larocque, Y. Atmos. Environ. Vol.38 (2004), p.147-161

[18] In Chinese. National Development and Reform Commission. Requirements for concentration limits for certain hazardous substances in lighting equipment. (2008)

[19] In Chinese. National Bureau of Statistics (NBS). China statistical yearbook 2012. Beijing, China: China Statistics Press. (2012)

[20] Quanyin Tan, Jinhui Li. Journal of Cleaner Production. Vol.81(2014), p.227-233

[21] Eckelman MJ, Anastas PT, Zimmerman JB. Environ Sci Technol. Vol.42 (2008), p.8564-8570

[22] Takahashi, F.; Kida, A.; Shimaoka, T. Sci. Total Environ. Vol.408 (2010), p.5472-5477

[23] In Chinese. National Development and Reform Commission (NDRC). Roadmap on phasing-out of incandescent lamps in China, Beijing, China. (2011).

[24] Earle, C. D. A.; Rhue, R. D.; Earle, J. F. K. Waste Manage. Res. Vol.17 (1999), p. 305-312

[25] In Chinese. Zheng Yun. Beifanghuanjing. Vol.22 (2010), p.24-27 